\title{
Bases biomoleculares do fotoenvelhecimento *
}

\author{
Molecular basis of photoaging
}

\author{
Suelen Montagner ${ }^{1}$
}

Adilson Costa ${ }^{2}$

\begin{abstract}
Resumo: Com o aumento da expectativa de vida, o estudo do processo de envelhecimento orgânico tem sido estimulado. O envelhecimento da pele, órgão que espelha os sinais do tempo, é processo de deterioração progressiva, tempo-dependente, e pode ser intensificado pela exposição solar, então designado fotoenvelhecimento. $\mathrm{O}$ dano das radiações sobre diversas estruturas celulares e cutâneas leva a alterações morfológicas nesses componentes, fruto de modificações biomoleculares. Muitas pesquisas são desenvolvidas com o intuito de combater ou minimizar os efeitos do fotoenvelhecimento, porém a principal estratégia nesse sentido continua sendo a prevenção, só conseguida pelo progressivo desvendar dos mecanismos fisiopatogênicos envolvidos nesse processo.

Palavras-chave: Envelhecimento; Envelhecimento da pele; Proteína supressora de tumor p53; Raios ultravioleta

Abstract: As a result of the increase in life expectancy, the study of the organic process of aging has been stimulated. Skin ageing, which reflects the signs of time, is a time-dependent process of progressive deterioration that can be intensified by sun exposure, which is known as photoaging. The damage of radiation on various cell structures and on the skin results in molecular and morphological changes to these components. Many research studies are performed to try to minimize the effects of photoaging; however, the main strategy to manage it is still prevention, which will only be achieved once we learn about the mechanisms involved in the process.

Keywords: Aging; Skin aging; Tumor suppressor protein p53; Ultraviolet rays
\end{abstract}

\section{INTRODUÇÃO}

Segundo a Organização Mundial da Saúde, entre 1950 e 2025 , a população brasileira acima de 60 anos crescerá 16 vezes, enquanto a população geral sofrerá aumento de cinco vezes. O aumento da expectativa de vida, uma realidade também nos países em desenvolvimento, tem estimulado o estudo do processo de envelhecimento. A pele expressa de forma visível a ação do tempo e por ele é transformada. Tratase, então, do envelhecimento intrínseco ou cronológico. No entanto, há, ainda, o envelhecimento extrínseco ou fotoenvelhecimento, decorrente da exposição a fatores ambientais, fundamental no resultado final do processo. $^{1}$
O envelhecimento implica alterações em nível celular, com diminuição da capacidade dos órgãos de executar suas funções normais, resultando provavelmente em doença e morte. ${ }^{2}$ Trata-se de deterioração progressiva, tempo-dependente, do organismo em resposta adaptativa às mudanças ambientais. ${ }^{3}$

Com o passar do tempo, ocorrem alterações moleculares que desencadeiam alterações orgânicas e, em última análise, levam ao envelhecimento. Um exemplo disso é o reparo no DNA telomérico. Telômeros são sequências de repetições nucleopeptídicas presentes no final dos cromossomos. ${ }^{4}$ Como a DNA-polimerase não consegue transcrever a sequên-

\footnotetext{
Aprovado pelo Conselho Editorial e aceito para publicação em 08.12.08.

* Trabalho realizado no Serviço de Dermatologia da Pontifícia Universidade Católica de Campinas (PUCCAMPINAS) - Campinas (SP), Brasil.

Conflito de interesse: Nenhum / Conflict of interest: None

Suporte financeiro: Nenhum / Financial funding: None

Médica formada pela Pontifícia Universidade Católica de São Paulo (PUC-SP) - Sorocaba (SP), Brasil. Residente de Clínica Médica do Hospital Municipal Dr. Mário Gatti (HMMG) - Campinas (SP), Brasil.

Coordenador dos Ambulatórios de Cosmiatria e Acne e do Núcleo de Pesquisa Clínica em Dermatologia da Pontifícia Universidade Católica de Campinas (PUCCAMPINAS) - Campinas (SP), Brasil. Mestre em Dermatologia pela Universidade Federal de São Paulo (UNIFESP/EPM) - São Paulo (SP), Brasil.

(C)2009 by Anais Brasileiros de Dermatologia
} 
cia final de bases presentes na fita de DNA durante a replicação, o tamanho telomérico se reduz a cada mitose. ${ }^{2}$ Essa redução do telômero foi associada ao envelhecimento celular. ${ }^{5-8}$

Segundo teoria desenvolvida em 1956 por Denham Harman, os radicais livres também estão envolvidos nesse processo de envelhecimento: eles provocariam dano celular, que seria acumulado durante a vida, resultando em aceleração de disfunções. ${ }^{9}$

De acordo com outros estudos, desvendou-se a degradação de produtos oxidados. Essa função é exercida pela proteossoma, protease multicatalítica, cuja atividade parece diminuir ao longo da vida. Com isso, notam-se degradação incompleta de proteínas oxidadas, aumento de agregados proteicos e aceleração da disfunção celular, o que, em última instância, leva ao envelhecimento celular. 9,10

O envelhecimento da pele, assim como de todo o organismo, também é fruto dessas alterações biomoleculares. $\mathrm{O}$ dano às fibras colágenas está intimamente envolvido nesse contexto. Os fibroblastos são responsáveis pelo metabolismo do colágeno, sintetizando procolágeno I, importante componente da matriz extracelular. Com a idade, ocorre desorganização no metabolismo do colágeno, reduzindo, assim, sua produção e aumentando sua degradação. ${ }^{9}$

A exposição solar, devido à radiação ultravioleta, por sua vez, intensifica o envelhecimento da pele, processo chamado de fotoenvelhecimento. ${ }^{11}$ Desse modo, portanto, conclui-se que o envelhecimento cutâneo envolve fatores intrínseco (cronológico) e extrínseco (solar). ${ }^{12}$

\section{FOTOENVELHECIMENTO}

Trata-se de processo cumulativo que depende do grau de exposição solar e da pigmentação cutânea. A pele envelhecida pelo sol apresenta-se amarelada, com pigmentação irregular, enrugada, atrófica, com telangiectasias e lesões pré-malignas. ${ }^{12}$

As alterações histológicas provocadas pelo fotoenvelhecimento são inúmeras. $\mathrm{Na}$ epiderme, notam-se o adelgaçamento da camada espinhosa e o achatamento da junção dermoepidérmica. ${ }^{13}$ Os queratinócitos envelhecidos, por sua vez, tornam-se resistentes à apoptose, ficando susceptíveis às mutações no DNA, processo implicado na carcinogênese. O número de melanócitos também se reduz, alterandose a densidade melanocítica. Isso favorece o surgimento de efélides, hipomelanose gotada, lentigos e nevos. As células de Langerhans também decrescem em número com a idade, resultando em perda da capacidade antigênica. ${ }^{11}$

O efeito solar imediato sobre a pele é a hiperpigmentação cutânea com atraso na formação de nova melanina, o qual é efeito reversível. A exposição solar prolongada e recorrente implica alterações definitivas na quantidade e distribuição de melanina na pele. A deposição de material amorfo na derme papilar, no lugar de tecido conectivo, é o principal elemento na diferenciação de envelhecimento cronológico e fotoenvelhecimento. ${ }^{12}$

As alterações morfológicas resultantes do fotoenvelhecimento são, em essência, diferentes das observadas no envelhecimento intrínseco. O paralelo entre tais alterações pode ser visto no quadro1.11-13

Nas células, os códigos proteicos são armazenados nos núcleos e nas mitocôndrias. As mitocôndrias contêm múltiplas cópias de DNA (mitocondrial) e as células contêm inúmeras mitocôndrias, produtoras de adenosina-trifosfato (ATP), que é uma molécula energética. As espécies reativas de oxigênio (reactive oxygen species: ROS) são produtos desse processo $\mathrm{e}$ podem danificar lipídeos, proteínas e também o próprio DNA. ${ }^{14,15}$

O DNA mitocondrial apresenta alta taxa de mutação devido a sua deficiência de histonas, baixa capacidade de reparo e proximidade aos ROS.15 Esse desequilíbrio entre o estresse oxidativo e as enzimas "varredoras" dos radicais livres tem sido responsabilizado como uma das causas do dano mitocondrial. 16,17

As mutações no DNA mitocondrial foram observadas com maior ênfase em peles fotoexpostas, quando comparadas às protegidas do sol.13-17 A deleção da 4,977-bp ("base pair") é a mutação mais encontrada nos tecidos envelhecidos. ${ }^{12,18-23}$ A radiação ultravioleta A (UVA) tem sido incriminada como indutora dessa deleção no DNA mitocondrial,24,25 ainda que essa alteração gênica possa ser detectada em tecidos não susceptíveis aos raios solares. ${ }^{19}$

A radiação ultravioleta (UV) penetra a pele e, de acordo com o comprimento de onda, interage com as diferentes células localizadas nas diferentes camadas. A radiação de ondas curtas (UVB: 290-320nm) é mais absorvida na epiderme e afeta predominantemente os queratinócitos, enquanto as ondas mais longas (UVA: $320-400 \mathrm{~nm}$ ) penetram de modo mais profundo e atingem queratinócitos da epiderme e fibroblastos da derme. ${ }^{26}$

Cada tipo de onda atua de modo específico. A UVA age indiretamente através da geração de ROS que atuam na ativação de fatores envolvidos na transcrição do DNA. Esse processo resulta em mutações no DNA mitocondrial. 26,27

A UVB, por sua vez, também gera espécies de ROS, porém sua principal ação é a indução direta de dano ao DNA. ${ }^{28}$ Os UVB são absorvidos pelo DNA e provocam sua mutação. Essa interação cria fotoprodutos diméricos como pirimidinas, que podem estar relacionadas a lesões cutâneas pré-malignas, porém 
QUADRO 1: Alterações cutâneas provocadas por envelhecimento intrínseco e extrínseco

\begin{tabular}{|c|c|c|c|}
\hline & $\begin{array}{l}\text { Envelhecimento intrínseco } \\
\text { (Cronológico) }\end{array}$ & & $\begin{array}{l}\text { Envelhecimento extrínseco } \\
\text { (Fotoenvelhecimento) }\end{array}$ \\
\hline - Rugas & Finas & & Profundas \\
\hline - Camada córnea & Inalterada & & Afilada \\
\hline - Células displásicas & Poucas & & Muitas \\
\hline - Fibras de colágeno & $\begin{array}{l}\text { Pequena alteração no tamanho } \\
\text { e organização }\end{array}$ & & $\begin{array}{l}\text { Grande alteração no tamanho e } \\
\text { organização }\end{array}$ \\
\hline - Fibras elásticas & Reorganizadas & $\downarrow$ & produção e $\uparrow$ degeneração \\
\hline - Folículo capilar & $\downarrow$ número e afinamento & $\downarrow$ & número e estrutura: perda capilar \\
\hline - Melanócitos & Normal & $\downarrow$ & número e melanina \\
\hline - Glândulas sebáceas e sudoríparas & $\downarrow$ número & $\downarrow$ & número: pele seca \\
\hline - Junção dermoepidérmica & Leve achatamento & & Importante achatamento \\
\hline - Microvasculatura & Área reduzida & & $\begin{array}{l}\text { Telangiectasias, equimoses, infiltrado } \\
\text { inflamatório perivascular. }\end{array}$ \\
\hline - Alterações benignas & Ceratose seborreica & & Ceratose seborreica \\
\hline - Alterações pré-malignas & - & & Ceratose actínica \\
\hline - Alterações malignas & - & & $\begin{array}{l}\text { Carcinoma basocelular } \\
\text { Carcinoma espinocelular }\end{array}$ \\
\hline
\end{tabular}

sem elucidação de relevância com outras manifestações do fotoenvelhecimento. ${ }^{29}$

As pirimidinas são compostos orgânicos semelhantes ao benzeno. A citosina, a timina e a uracila são bases que derivam das pirimidinas. Apresenta-se na Figura 1 a formação das pirimidinas. ${ }^{29}$

Aminoácidos aromáticos de proteínas da camada córnea da pele absorvem grande parte da radiação UVB antes que essa atinja as moléculas de ácido nucleico. A luz UVB danifica o DNA, na maioria das vezes, por meio da formação de fotoprodutos diméricos próximos a bases pirimidínicas: dímero pirimidina ciclobutano (CPD) (Figura 1A) e 6,4-pirimidona-pirimidina (6,4-PP) (Figura 1B). ${ }^{29}$

Quando expostos a radiações UVA/UVB, os produtos do tipo 6,4-PP são prontamente convertidos nos isômeros "Dewar" (Figura 1B), que são moderadamente fotoativáveis e podem ser revertidos à 6,4-PP sob radiação de ondas curtas. Falha no reparo desse processo propicia mutações nas células epidérmicas, gerando o desenvolvimento de células cancerosas. ${ }^{29}$

Timina-citosina (TC) e citosina-citosina (CC) são as CPDs mais mutagênicas, e suas mutações se

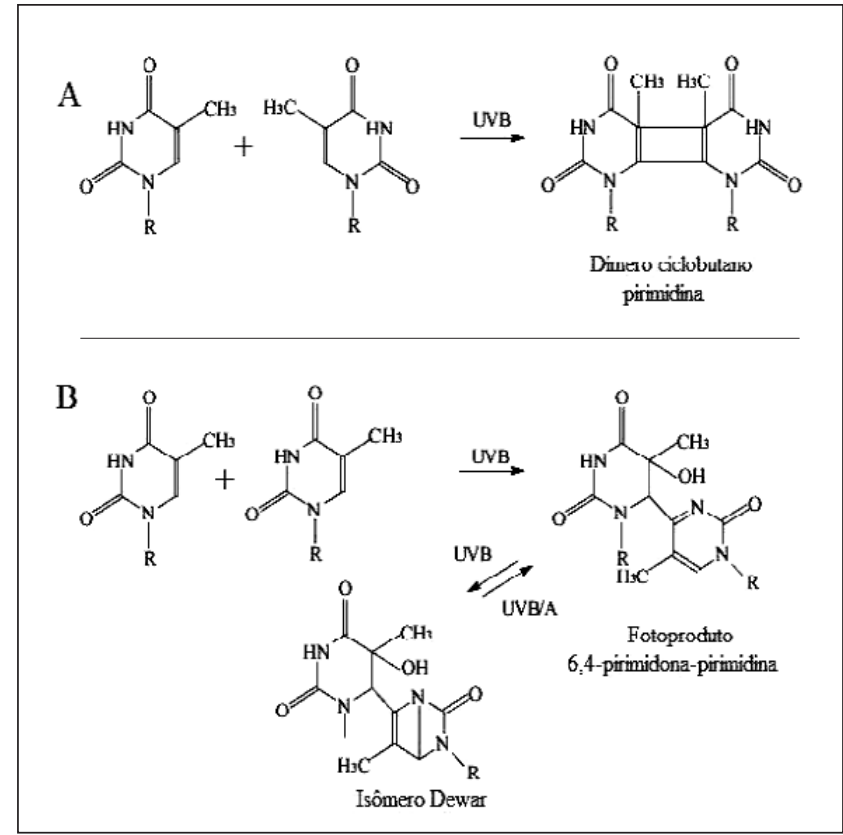

Figura 1: Formação de dímero ciclobutano pirimidina (A), fotoproduto 6,4-pirimidona-pirimidina e isômero Dewar (B), a partir de bases pirimidínicas expostas à radiação UVB 
relacionam, frequentemente, ao gene p53. As CPDs são as maiores responsáveis pelas mutações em mamíferos, já que não são facilmente reparadas, ao contrário das 6,4-PP. Parece haver distintas respostas celulares frente à UVA e à UVB, como a menor ativação do p53 pela UVA e ativação mais intensa pela UVB, o que pode determinar diferentes mutações induzidas por cada uma dessas. ${ }^{29}$

A fraca ativação do p53 pela UVA aumenta a probabilidade de o dímero pirimidona liderar a mutação e danificar a replicação, frente à pouca indução de reparo do DNA mediada pelo p53. Nesse contexto, a probabilidade de uma célula mutante sobreviver e tornar-se câncer de pele aumenta, uma vez que a apoptose mediada pelo p53 está insuficiente. Se essa hipótese for verdadeira, os dímeros UVA induzidos são mais mutagênicos devido à baixa proteção aos danos do DNA. ${ }^{29}$

A radiação ultravioleta também altera o RNA e implica a formação de proteínas disfuncionantes. Um bloqueio na transcrição do RNA por um fotoproduto de DNA permite a ativação de p53, induzindo a apoptose de queratinócitos irradiados. ${ }^{29}$

A exposição aos raios UVA desencadeia dois fatores relacionados ao fotoenvelhecimento: indução de metaloproteinases da matriz (MMP) e mutação mitocondrial (já mencionada). ${ }^{26,30,31}$

Os produtos reativos de oxigênio, formados pela radiação ultravioleta, ativam quinases, que aumentam a expressão e ativam fatores de transcrição como a proteína 1 (AP-1) e o fator $\mathrm{kB}$ de transcrição nuclear (NF-kB). ${ }^{12}$

A AP-1 ativada estimula a transcrição de genes de enzimas desintegradoras da matriz, como as metaloproteínas (MMP1, MMP3, MMP9). ${ }^{32,33}$ A MMP1 cliva os colágenos tipo I e tipo III da pele, preparando-os para serem degradados pelas MMP3 e MMP9. Nesse processo ocorre também redução do colágeno VII, importante componente da junção dermoepidérmica. ${ }^{12,34} \mathrm{O}$ NF$\mathrm{kB}$ ativado, por sua vez, estimula citocinas inflamatórias (IL1, IL6, TNF $\alpha$ ), atraindo neutrófilos e colagenases, associados à degradação de colágeno. 35

Além de estar relacionada à degradação de colágeno, a radiação também contribui na redução de sua síntese. A formação de colágeno I na derme papilar é reduzida pelo efeito do dano solar, que diminui a expressão do gene dos protocolágenos tipos I e III. 36,37 Os mecanismos que contribuem para tal feito são a indução da transcrição do fator $\mathrm{AP}^{-138}$ e a diminuição do receptor do fator de crescimento $\beta$ (TGF- $\beta$ ) tipo II. 39 O colágeno alterado, por si, reduz a síntese no colágeno novo. 40,41 A pouca adesão dos fibroblastos ao colágeno alterado também diminui a neocolagênese. ${ }^{42}$ Nesse cenário, fica evidente a resposta molecular à agressão solar. Esses mecanismos são resumidamente ilustrados na figura 2.14-41

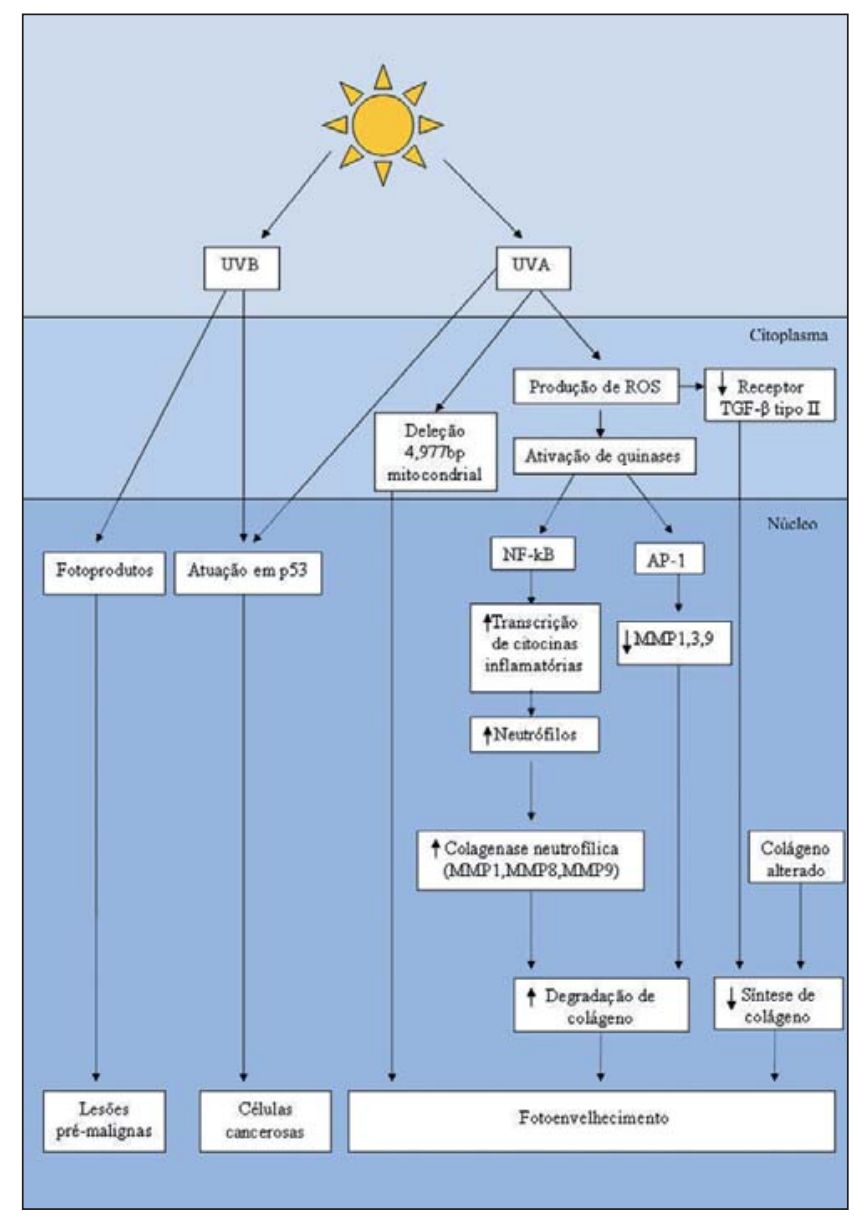

FIgUra 2: Efeitos celulares da radiação ultravioleta. UVB formando fotoprodutos que levam a lesões pré-malignas. Atuação de UVA/UVB sobre p53, produzindo células cancerosas. Deleção de 4,977 bp mitocondrial e produção de ROS pela radiação UVA,

levando, em última análise, ao fotoenvelhecimento

É tamanha a importância da exposição ultravioleta na degradação da pele, que, segundo estudos, o uso tópico de filtro solar fator 15 (FPS) em ratos antes da exposição ao sol reduz a ativação de elastina (um indicador de dano solar) em $70 \%$ dos casos, além de prevenir mutações do gene que codifica a proteína p53, que contribui para o desenvolvimento de câncer de pele. 43,44

A proteína p53 é codificada pelo gene TP53 localizado no cromossomo 17 . Trata-se de fosfoproteína de 390 aminoácidos, conhecida como "guardiã de genoma". ${ }^{45}$ Ela está envolvida no controle da proliferação celular, reparo do DNA e morte celular. Em condições normais, apresenta-se em baixa concentração. Essa concentração reduzida é consequência de sua curta meia-vida e dificulta sua detecção por meio de métodos imuno ou histoquímicos convencionais. Em contrapartida, quando sob mutação, a proteína p53 apresenta meia-vida mais estável, facilitando sua identificação, uma vez que se acumula. Desse modo, a detecção da proteína p 53 por métodos convencionais sugere a ocorrência de mutação. ${ }^{46}$ 
Normalmente, a p53 bloqueia o ciclo celular quando esse sofre mutação no DNA, induzindo a apoptose de células danificadas. Tanto o envelhecimento intrínseco quanto o extrínseco podem ativar a p53. Alteração na estrutura telomérica, como uma quebra, também ativa a p53 e leva à apoptose ou ao envelhecimento. Portanto, ambos, envelhecimento e dano ao DNA, reduzem a estrutura telomérica e ativam a 553 , levando a envelhecimento e apoptose. ${ }^{45}$

\section{SIRT: O IMORTALIZADOR CELULAR}

Sirt é abreviatura de "sir-2", em inglês "sir-two" ("silent information regulator $\underline{2}$ "). ${ }^{47}$ Trata-se de proteína da família das sirtuínas, que ajuda a prolongar a vida celular enquanto modula o número de proteínas reparadoras do DNA. É deacetilase NAD-dependente (NAD: nicotinamida adenina dinucleotídeo), que possui importância no metabolismo e na sinalização celular. ${ }^{47-49}$ A deacetilase remove o grupo acetil do grupo amina de resíduos de lisina e é conservada em bactérias eucariontes. Sua atividade enzimática é regulada pela energia celular. ${ }^{49}$

Em humanos, há sete homólogos da SIR2 (Sirt1 até 7). Dessas, Sirt1 é a SIR2 ortóloga, ou seja, proteína semelhante à encontrada em outras espécies). Sirt1 age negativando a diferenciação de músculos e de células lipídicas e possivelmente contribui com a restrição calórica em mamíferos. Foram descobertos vários substratos da Sirt1, que incluem histonas, o gene da p53, fatores de transcrição Foxo, TAF68 e $\mathrm{Ku} 70$. Esses substratos sugerem que a Sirt1 esteja envolvida com apoptose, regulação do ciclo celular, transcrição, entre outras vias reguladoras celulares. ${ }^{49}$

A Sirt promove a sobrevivência celular ao deacetilar a p53, regulando negativamente sua transcrição. Esses dados corroboram a hiperacetilação da p53 e o aumento da apoptose induzida pela radiação observados em ratos com deficiência de Sirt1.52 Isso sugere seu papel de prevenção do envelhecimento celular e apoptose induzida por DNA danificado ou estresse. 50

Um recente estudo demonstrou que a DBC1 (deleted in breast cancer 1), proteína formada a partir do gene DBC1, ausente em pessoas com câncer de mama, atua inibindo a Sirt1 em células humanas. Isso favorece o aumento da acetilação da p53. Em contrapartida, a depleção da DBC1 endógena pela interferência do RNA estimula a deacetilação da p53 mediada pela Sirt1 e inibe a apoptose dependente da p 53.51

A expressão elevada da Sirt aumenta o estresse oxidativo; quando moderada, sua expressão estimula a resistência a esse efeito, assim como à apoptose.
Esses dados sugerem a importância dessa enzima no retardo do envelhecimento e na resistência ao estresse de células cardíacas. 52

Muitos estudos estão sendo realizados atualmente sobre esse tema, embora pouco se saiba sobre os mecanismos reguladores da atividade da Sirt1. ${ }^{47-55}$ Essa família proteica tem sido objeto de pesquisas atuais, que buscam cura para cânceres, doença de Alzheimer, além de controle do metabolismo lipídico e prevenção do envelhecimento. 53,54

A restrição calórica tem sido a base para tais estudos. Ela aumenta o tempo de vida em organismos testados e, em mamíferos, exerce potente efeito supressor tumoral. Nos eucariontes inferiores, o gene da SIR2 tem sido relacionado à promoção da saúde, em virtude da restrição calórica. A Sirt1 tem sido apresentada como fator de melhora de doenças degenerativas associadas ao envelhecimento, como a neurodegeneração (doença de Alzheimer) e o declínio metabólico. A restrição calórica inibe a formação tumoral, seja ela espontânea ou induzida. 53,54

Tem-se a perspectiva de que o melhor conhecimento da modulação da Sirt possa favorecer o estudo do equilíbrio homeostático, tão perturbado nas doenças humanas. De acordo com estudos atuais, a Sirt1 vem-se apresentando como a chave reguladora da defesa e sobrevivência celulares em resposta ao estresse. ${ }^{55}$

\section{CONCLUSÃO}

Mesmo diante de avanços biomoleculares e promessas cosméticas, a melhor forma de combater o fotoenvelhecimento e suas consequências é a prevenção. O número de rugas da pele está fortemente associado às horas de exposição solar durante a vida. Pode-se, então, usar esse sinal clínico como marcador preditivo de risco de se desenvolver câncer de pele, uma vez que a quantidade de rugas pode ser marcador da exposição solar durante a vida. ${ }^{56}$

O método mais efetivo de prevenir o fotoenvelhecimento e suas malignidades é evitar a exposição direta aos raios ultravioleta, fazendo uso de barreiras físicas como chapéu e vestuário adequado, principalmente nas populações que trabalham diretamente expostas ao sol, muito comum em nosso país.

A conscientização do uso diário do filtro solar é alvo de campanhas da Sociedade Brasileira de Dermatologia e, sem dúvida, é o principal caminho para evitar os efeitos danosos da radiação não só no retardo da instalação do fotoenvelhecimento, mas, principalmente, na prevenção de seu efeito mais temido, o câncer da pele. 


\section{REFERÊNCIAS}

1. Pereira S. Dermatoses no idoso. In: Rotta O. Guia de Dermatologia: clínica, cirúrgica e cosmiátrica. São Paulo: Manole; 2008. p.567-91.

2. Yaar M, Eller MS, Gilchrest BA. Fifty years of skin aging. J Investig Dermatol Symp Proc. 2002;7:51-8.

3. Yaar M. Molecular mechanisms of skin aging. Adv Dermatol. 1995;10:63-75.

4. Meyne J, Ratliff R, Moyzis R. Conservation of the human telomere sequence (TTAGGC)n among vertebrates. Proc Natl Acad Sci USA. 1989;86:7049-53.

5. Kosmadari MG, Gilchrest BA. The role of telomeres in skin aging/photoaging. Micron. 2004;35:155-9.

6. Dimri GP, Lee X, Basile G, Acosta M, Scott G, Roskelley $\mathrm{C}$, et al. A biomarker that identifies senescent human cells in culture and in aging skin in vivo. Proc Natl Acad Sci USA. 1995;92:9363-7.

7. Yaar M, Gilchrest BA. Skin aging: postulated mechanisms and consequent changes in structure and function. Clin Geriatr Med. 2001;17:617-30.

8. Rabe JH, Mamelak AJ, McElgunn PJ, Morison WL, Sauder DN. Photoaging: mechanisms and repair. J Am Acad Dermatol. 2006;55:1-19.

9. Widmer R, Ziaja I, Grune T. Protein oxidation and degradation during aging: Role in skin aging and neurodegeneration. Free Radic Res. 2006;40:1259-68.

10. Kraft DC, Deacaris CC, Rattan SI. Proteasomal oscillation during mild heat shock in aging human skin fibroblasts. Ann N Y Acad Sci. 2006;1067:224-7.

11. Wulf HC, Sandby-Møller J, Kobayasi T, Gniadecki R. Skin aging and natural photoprotection. Micron. 2004; 35: 185-91.

12. Landau M. Exogenous factors in skin aging. Curr Probl Dermatol. 2007;35:1-13.

13. Berneburg M, Grether-Beck S, Kürten V, Ruzicka T, Briviba K, Sies H, et al. Singlet oxygen mediates the UVA-induced generation of the photoaging-associated mitochondrial common deletion. J Biol Chem. 1999; 274:15345-9.

14. Ray AJ, Turner R, Nikaido O, Rees JL, Birch-Machin MA. The spectrum of mitochondrial DNA deletions is a ubiquitous marker of ultraviolet radiation exposure in human skin. J Invest Dermatol. 2000;115:674-9.

15. Koch H, Wittern KP, Bergemann J. In human keratinocytes the Common Deletion reflects donor variabilities rather than chronologic aging and can be induced by ultraviolet A irradiation. J Invest Dermatol. 2000;117:892-7.

16. Harbottle A, Krishnan KJ, Birch-Machin MA. Implications of using the ND1 gene as a control region for real-time PCR analysis of mitochondrial DNA deletions in human skin. $J$ Invest Dermatol. 2004; 122:1518-21.

17. Krishnan KJ, Harbottle A, Birch-Machin MA. The use of a 3895 bp mitochondrial DNA deletion as a marker for sunlight exposure in human skin. J Invest Dermatol. 2004;123:1020-4.

18. Shigenaga MK, Hagen TM, Ames BN. Oxidative damage and mitochondrial decay in aging. Proc Natl Acad Sci USA. 1994;91:10771-8.

19. Eshaghian A, Vleugels R, Canter JA, McDonald MA,
Stasko T, Sligh JE. Mitochondrial dna deletions serve as biomarkers of aging in the skin, but are typically absent in nonmelanoma skin cancers. J Invest Dermatol. 2006;126:336-44.

20. Shoffner JM, Lott MT, Voljavec AS, Soueidan SA, Costigan DA, Wallace DC. Spontaneous Kearns-Sayre/chronic external ophthalmoplegia plus syndrome associated with a mitochondrial DNA deletion: a slip-replication model and metabolic therapy. Proc Natl Acad Sci USA. 1989;86:7952-6.

21. Lu CY, Lee HC, Fahn HJ, Wei YH. Oxidative damage elicited by imbalance of free radical scavenging enzymes is associated with largescale mtDNA deletions in aging human skin. Mutat Res. 1999;423:11-21.

22. Cortopassi GA, Arnheim N. Detection of a specific mitochondrial DNA deletion in tissues of older humans. Nucleic Acids Res. 1990;18:6927-33.

23. Cortopassi GA, Shibata D, Soong NW, Arnheim N. A pattern of accumulation of a somatic deletion of mitochondrial DNA in aging human tissues. Proc Natl Acad Sci USA. 1992;89:7370-4.

24. Berneburg M, Plettenberg H, Medve-König K, Pfahlberg $\mathrm{A}$, Gers-Barlag $\mathrm{H}$, Gefeller $\mathrm{O}$, et al. Induction of the photoaging-associated mitochondrial common deletion in vivo in normal human skin. J Invest Dermatol. 2004; 122:1277-83.

25. Birch-Machin MA, Tindall M, Turner R, Haldane F, Rees JL. Mitochondrial DNA deletions in human skin reflect photo- rather than chronologic aging. J Invest Dermatol. 1998;110:149-52.

26. Krutmann J. The role of UVA rays in skin aging. Eur J Dermatol. 2001;11:170-1.

27. Hernandez-Pigeon H, Jean C, Charruyer A, Haure MJ, Baudouin C, Charveron M, et al. UVA induces granzyme $\mathrm{B}$ in human keratinocytes through MIF: implication in extracellular matrix remodeling. J Biol Chem. 2007;282:8157-64.

28. Stege H, Roza L, Vink AA, Grewe M, Ruzicka T, GretherBeck S, et al. Enzyme plus light therapy to repair DNA damage in ultraviolet-B-irradiated human skin. Proc Natl Acad Sci USA. 2000;97: 1790-5.

29. Svobodova A, Walterova D, Vostalova J. Ultraviolet light induced alteration to the skin. Biomed Pap Med Fac Univ Palacky Olomouc Czech Repub. 2006;150:25-38.

30. Wang XY, Bi ZG. UVB-irradiated human keratinocytes and interleukin-1alpha indirectly increase MAP kinase/AP-1 activation and MMP-1 production in UVAirradiated dermal fibroblasts. Chin Med J (Engl). 2006;119:827-31.

31. Watanabe $H$, Shindo $K$, Ida $H$, Tanaka H, Nagasaka T, Shiozawa Z. Aging effects of sympathetic reflex activities on skin nerves. Gerontology. 2003;49:366-73.

32. Angel P, Szabowski A, Schorpp-Kistner M. Function and regulation of AP-1 subunits in skin physiology and pathology. Oncogene. 2001;20:2413-23.

33. Fisher GJ, Kang S, Varani J, Bata-Csorgo Z, Wan Y, Datta $S$, et al. Mechanisms of photoaging and chronological skin aging. Arch Dermatol. 2002;138:1462-70.

34. Moon HJ, Lee SR, Shim SN, Jeong SH, Stonik VA, 
Rasskazov VA, et al. Fucoidan inhibits UVB-induced MMP-1 expression in human skin fibroblasts. Biol Pharm Bull. 2008;31:284-9.

35. Reelfs O, Tyrrel RM, Pourzand C. Ultraviolet a radiationinduced immediate iron release is a key modulator of the activation of NF-kappaB in human skin fibroblasts. J Invest Dermatol. 2004;122:1440-7.

36. Griffiths C, Russman AN, Majmudar G, Singer RS, Hamilton TA, Voorhees JJ. Restoration of collagen formation in photodamaged human skin by tretinoin (retinoic acid). N Engl J Med. 1993;329:530-5.

37. Fischer GJ, Datta S, Wang Z, Li XY, Quan T, Chung JH, et al. c-Jun-dependent inhibition of cutaneous procollagen transcription following ultraviolet irradiation is reversed by all-trans retinoic acid. J Clin Invest. 2000; 106:663-70.

38. Chung KY, Agarwal A, Uitto J, Mauniel A. An AP-1 binding sequence is essential for regulation of the human alpha2(I) collagen (COL1A2) promoter activity by transforming growth factor-beta. J Biol Chem. 1996;271:3272-8.

39. Quan T, He T, Kang S, Voorhees JJ, Ficher GJ. Solar ultraviolet irradiation reduces collagen in photoaged human skin by blocking transforming growth factorbeta type II receptor/Smad signaling. Am J Pathol. 2004;165:741-51.

40. Varani J, Perone P, Fligiel SE, Fischer GJ, Voorhees JJ. Inhibition of type I protocollagen production in photodamage: correlation between presence of high molecular weight collagen fragments and reduced procollagen synthesis. J Invest Dermatol. 2002;119:122-9.

41. Fligiel SE, Varani J, Datta SC, Kang S, Fisher GJ, Voorhees JJ. Collagen degradation in aged/photodamaged skin in vivo and after exposure to matrix metalloproteinase-1 in vitro. J Invest Dermatol. 2003;120:842-8.

42. Varani J, Schuger L, Dame MK, Leonard C, Fliegiel SE, Kang S, et al. Reduced fibroblast interaction with intact collagen as a mechanism for depressed collagen synthesis in photodamaged skin. J Invest Dermatol. 2004; 122:1471-9.

43. Hadshiew IM, Eller MS, Gilchrest BA. Skin aging and photoaging: the role of DNA damage and repair. Am J Contact Dermat. 2000;11:19-25.

44. Tsukahara K, Moriwaki S, Hotta M, Fujimura T, Sugiyama-Nakagiri Y, Sugawara S, et al. The effect of sunscreen on skin elastase activity induced by ultraviolet-A irradiation. Biol Pharm Bull. 2005;28:2302-7.

45. Gilchrest BA. Skin aging 2003: recent advances and current concepts. Cutis. 2003;72:5-10.
46. Bertelli E, Queiroz R, Rodrigues F, Tapparo L, Jr Silva WA, Tajara E. Carcinogênese cutânea no sudeste do Brasil: análise do gene tp53 em tumores cutâneos não melanocíticos. An bras Dermatol. 2002;77:33-4.

47. Tanno M, Sakamoto J, Miura T, Shimamoto K, Horio Y. Nucleocytoplasmic shuttling of the NAD+-dependent histone deacetylase SIRT1. J Biol Chem. 2007; 282: 6823-32.

48. Sasaki T, Maier B, Bartke A, Scrable H. Progressive loss of SIRT1 with cell cycle withdrawal. Aging Cell. 2006;5:413-22

49. Blander G, Olejnik J, Krzymanska-Olejnik E, McDonagh T, Haigis M, Yaffe MB, et al. SIRT1 shows no substrate specificity in vitro. J Biol Chem. 2005;280:9780-5.

50. Dal Farra C, Domloge N. SIRT1, the human homologue to SIR2, is expressed in human skin and in cultured keratinocytes fibroblasts and HaCaT cells; and its levels is closely related to stress and aging. $\mathrm{J}$ Cosmet Sci. 2006;57:187-8.

51. Zhao W, Kruse JP, Tang Y, Jung SY, Qin J, Gu W. Negative regulation of the deacetylase SIRT1 by DBC1. Nature. 2008; 451:587-90.

52. Alcendor R, Gao S, Zhai P, Zablocki D, Holle E, Yu X, et al. Sirt1 regulates aging and resistance to oxidative stress in the heart. Circ Res. 2007;100:1512-21.

53. Firestein R, Blander G, Michan S, Oberdoerffer P, Ogino $\mathrm{S}$, Campbell J, et al. The SIRT1 deacetylase suppresses intestinal tumorigenesis and colon cancer growth. PLoS ONE. 2008;3:e2020.

54. Kim D, Nguyen MD, Dobbin MM, Fischer A, ananbenesi F, Rodgers JT, et al. SIRT1 deacetylase protects against neurodegeneration in models for Alzheimer's disease and amyotrophic lateral sclerosis. EMBO J. 2007;26:3169-79.

55. Anastasiou D, Krek W. SIRT1: linking adaptive cellular responses to aging-associated changes in organismal physiology. Physiology (Bethesda). 2006;21:404-10.

56. Akiba S, Shinkura R, Miyamoto K, Hillebrand G, Yamaguchi $\mathrm{N}$, Ichihashi $\mathrm{M}$. Influence of chronic UV exposure and lifestyle on facial skin photo-aging-results from a pilot study. J Epidemiol. 1999;9:S136-42.

ENDEREÇO PARA CORRESPONDÊNCIA / MAILING ADDRESS:
Suelen Montagner
Endereço: Rua Maria Monteiro, 477 ap 21 -
Cambuí
13025150 Campinas - SP
Tel./fax: $193295-4241$
E-mail: suelen_montagner@yaboo.com.br

ENDEREÇO PARA CORRESPONDÊNCIA / MAILING ADDRESS:

Suelen Montagner

Endereço: Rua Maria Monteiro, 477 ap 21 bui

Tel./fax: 19 3295-4241

E-mail: suelen_montagner@yaboo.com.br 